Mineração

\title{
Caracterização e determinação do comportamento de consolidação da polpa de bauxita
}

\author{
(Characterization and consolidation behavior of the bauxite slurry)
}

\section{Christine Rabello Nascimento}

Engenheira Química, MSc.,

DSc., Pesquisadora

Coordenação de Processos

Minerais - COPM

Centro de Tecnologia Mineral -

CETEM

E-mail: crabello@cetem.gov.br

\section{Resumo}

A sedimentação e a consolidação do minério decorrente de uma parada no processo de bombeamento de polpas em dutos podem ocasionar dificuldades numa nova partida operacional. Nesse contexto, a coesão do material sedimentado tem relevância e está relacionada a determinados fatores, tais como a composição dos minerais na polpa, as características dos minerais e a distribuição de tamanhos das partículas. Esse trabalho tem por objetivo avaliar, mediante medidas reológicas, a variação da coesão das partículas sedimentadas de uma polpa de bauxita em função do tempo. O minério de bauxita utilizado foi devidamente caracterizado, sendo composto, predominantemente, por gibbsita, hematita e caulinita e contendo um elevado teor de finos - cerca de $45 \%$ das partículas tem tamanho inferior a $38 \mu \mathrm{m}$. Pelas curvas de tensão versus tempo, foi observado que antes de 4 horas, praticamente, todo material já havia se sedimentado. Após 24 horas de assentamento, ocorreu um ligeiro acréscimo da tensão na ruptura do sedimento.

Palavras-chave: Caracterização da bauxita, polpa de minério, reologia, mineroduto, sedimentação, consolidação.

\begin{abstract}
Ore particle settling and consolidation due a stop of slurry pumping may cause troubles in the restarting process. So, the cohesion of the sediment is an important issue, which is related to the mineral composition and the size's distribution of the particles in the slurry. The objective of this study is to evaluate by rheological measurements the changes in the cohesion of bauxite settled particles in function of time. The ore sample is comprised mainly of gibbsite, hematite and kaolinite, whose amount of fine grounded material is very high - about $45 \%$ of the particles are smaller than $38 \mu \mathrm{m}$. The settling practically finished before four hours and an increment of the tension in the rupture of the sediment was observed after 24 hours of rest.
\end{abstract}

Keywords: Bauxite characterization, mineral slurry, settling, consolidation, rheology, pipeline. 


\section{Introdução}

O Brasil é um país com grande extensão territorial em que a atividade de mineração se encontra, geralmente, distante dos centros de produção ou de consumo do país. O transporte de minérios pela malha rodoviária ou ferroviária é dispendioso ou carece de infraestrutura adequada, o que torna atrativa a opção do seu transporte sob a forma de polpa, via minerodutos.

Para efeito de transporte em dutos, as lamas ou polpas minerais podem ser classificadas quanto a sua tendência à sedimentação. Sabe-se que quando a turbulência difusiva do fluido de transporte (geralmente água) for insuficiente para manter as partículas sólidas não-coloidais em suspensão, haverá sedimentação no fundo da tubulação. Uma polpa com tendência à sedimentação tende a estratificar sob fluxo em dutos horizontais e inclinados, nas vazões usuais empregadas nesse tipo de operação, ou seja, ocorre uma distribuição não-uniforme das partículas - um gradiente de concentração - ao longo da seção transversal do duto (Matousek, 2005). O fluxo é considerado estratificado quando uma certa quantidade de sólidos forma um leito granular, que pode ser estacionário ou deslizante.

Uma parada eventual no processo de bombeamento de polpas com alto teor de sólidos pode ser especialmente crítica na medida em que o sedimento formado é capaz de obstruir a tubulação e dificultar o retorno da operação de bombeamento. $\mathrm{O}$ grau de compactação do sedimento é um parâmetro que deve ser determinado, sendo que testes de penetração podem ser usados para essa finalidade (Bragança \& Silva, 2007). Como alternativa aos testes de penetração, nesse trabalho foram empregados testes reológicos, cuja sensibilidade permite, inclusive, avaliar a influência de aditivos na coesão do sedimento formado (Araújo \& Nascimento, 2008).

É importante salientar que a metodologia em questão desconsidera o efeito de compactação devido à pressão hidrostática, que será relevante quando a altura da coluna de fluido sobre o sedimento for elevada. Contudo, a variação relativa da coesão do sedimento em decorrência de variáveis, tais como o teor de finos, o $\mathrm{pH}$ e a presença de espécies químicas capazes de interagir com a superfície das partículas para uma dada concentração de polpa, pode ser facilmente observada através do método reológico.

O desenvolvimento de modelos para a descrição do fenômeno de sedimentação/consolidação de partículas sólidas é uma matéria relevante em diversas áreas do conhecimento. Sabese que a velocidade de sedimentação de uma partícula é função de sua forma, densidade, tamanho, superfície sólida na vizinhança, concentração local e da viscosidade do fluido no qual está imersa. Sabe-se, ainda, que o aumento da concentração local faz com que a velocidade de sedimentação da partícula diminua (sedimentação impedida), na medida em que decresce a área livre de ascensão do fluido (Dankers \& Winterwerp, 2007). Mesmo quando a polpa é diluída ou constituída por partículas de diferentes tamanhos, as interações podem ocorrer, na medida que as partículas ou os flocos se aproximam. Quando a concentração local for muito alta, as partículas tenderão a manter contato umas com as outras, estabelecendo uma malha estruturada (tipo gel). A partir da concentração onde ocorre contato físico entre flocos ou partículas, tem início a consolidação do sedimento formado, em que o fluido contido no espaço intersticial vai sendo, progressivamente, expulso, até que um valor-limite de compactação do sedimento seja atingido. Antes que esse limite seja alcançado, a resistência à compactação cresce com o tempo em decorrência do aumento da repulsão eletrostática e da fricção mecânica ocasionados pela aproximação das partículas (Boudreau \& Bennett, 1999).

Além disso, partículas muito pequenas, como os argilo-minerais, possuem um comportamento diferenciado em virtude da sua grande área superficial e conseqüente capacidade de agregação, conferindo a característica coesiva ao sedimento (Torfs et al., 1996). De um modo geral, os sedimentos podem ser classificados como coesivos e nãocoesivos em decorrência da presença de material cimentante.

\section{Materiais e métodos}

Uma amostra de polpa de bauxita originada do norte do Estado do Pará (Brasil), já beneficiada pelo fornecedor, foi utilizada como recebida para a execução dos ensaios reológicos. A polpa possuía concentração de $50 \%(\mathrm{p} / \mathrm{p})$, a qual foi mantida constante em todos os testes reológicos realizados. Em um dos testes, foi feita a alteração do $\mathrm{pH}$ da polpa de 6,8 para 9,5, mediante a adição de solução de $\mathrm{NaOH}$.

O minério foi caracterizado quanto a sua distribuição granulométrica, morfologia e composições química e mineralógica.

A classificação granulométrica foi feita com a utilização de peneiras da série Tyler $\sqrt{2}$, com aberturas no intervalo de 48 a 400 meshes.

A análise de difração de raios $\mathrm{X}$ (DRX) foi feita através do equipamento Bruker-AXS D5005, com radiação Co K $\alpha$. Foi utilizado o método do pó, na faixa de 5 a $80^{\circ}(2 \theta)$, e a interpretação qualitativa foi efetuada por comparação com padrões contidos no banco de dados PDF02 (ICDD, 1996) em software Bruker DiffracPlus.

A análise semiquantitativa de fluorescência de raios $\mathrm{X}$ (FRX) foi efetuada em aparelho Bruker-AXS (Mod. S-4 Explorer) com tubo de ródio.

A caracterização microestrutural da fração mais fina da amostra (partículas com tamanho inferior a $38 \mu \mathrm{m}$ ) foi feita com microscópio eletrônico de varredura (MEV) LEO S440, equipado com sistema de microanálise por espectrometria de raios X (EDS) OXFORD Link ISIS 300, que possibilitou a realização de análises pontuais para a identificação elementar nas regiões de interesse.

Os ensaios reológicos foram feitos em reômetro da marca HAAKE, modelo 
RheoStress 1, utilizando rotor tipo vane 2blade-ref 222-1599. A amostra de polpa foi deixada em repouso por períodos predeterminados dentro do copo do reômetro, com o rotor já imerso na posição de teste. Após esse período, o teste era iniciado, sendo determinada a tensão resultante da deformação aplicada pelo rotor. Durante o teste, a velocidade de rotação era mantida constante igual a 0,287 RPM. Dessa forma, pôde ser observado o ponto de ruptura do sedimento formado como um valor máximo de tensão, de forma análoga ao que é feito nas análises para determinação da tensão limite de escoamento de suspensões (Dzui \& Boger, 1985).

\section{Resultados e discussão}

De acordo com os resultados da análise granulométrica, havia uma grande proporção de partículas finas na polpa, cujo tamanho estava abaixo de $38 \mu \mathrm{m}$ (Tabela 1). Para efeito de escoamento, a presença de finos pode causar aumento da viscosidade aparente (Bhattacharya et al., 1998) e, particularmente, no caso de a proporção de partículas coloidais ser alta, os efeitos de carga e demais propriedades da superfície das partículas passam a ter relevância no comportamento de fluxo da suspensão. No tocante à coesão do minério sedimentado, espera-se uma maior ocorrência de argilo-minerais na fração mais fina, o que pode ocasionar o aumento dessa propriedade, em comparação com a polpa deslamada.

As principais fases cristalinas identificadas na amostra por difração de raios $\mathrm{X}$ (DRX) foram as dos minerais gibbsita, hematita e caulinita. A caulinita é considerada um argilo-mineral com baixas propriedades coesivas (Dankers $\&$ Winterwerp, 2007). Contudo sua contribuição para a consolidação da bauxita sedimentada ainda não foi estudada, consistindo num assunto de interesse para a continuidade desse trabalho.

De um modo geral, as composições das principais frações granulométricas do minério foram similares (Figura 1), com exceção da fração mais fina (amostra 7), que apresentou queda no teor de alumina e um aumento no teor de sílica e ferro $\left(\mathrm{Fe}_{2} \mathrm{O}_{3}\right)$. Contudo a análise de fluorescência de raios $\mathrm{X}$ (FRX) não é conclusiva quanto às proporções de gibbsita e caulinita presentes nas frações, visto que a quantidade relativa a ambos minerais aparece inserida no percentual de $\mathrm{Al}_{2} \mathrm{O}_{3}$. Da mesma forma, o percentual de $\mathrm{SiO}_{2}$ abrange os minerais caulinita e quartzo. Apesar de o quartzo estar presente em quantidade insuficiente para ser detectado pela técnica de DRX, partículas desse mineral puderam ser observadas por microscopia eletrônica. Os valores elevados de perda ao fogo estão, provavelmente, relacionados à eliminação de água estrutural da gibbsita e da caulinita e, portanto, esse resultado não pode ser usado para a quantificação desses minerais. Sendo assim, para que a determinação das quantidades

Tabela 1 - Análise granulométrica da bauxita lavada.

\begin{tabular}{c|c|c|c}
\hline $\begin{array}{c}\text { Número da } \\
\text { amostra }\end{array}$ & $\begin{array}{c}\text { Abertura de } \\
\text { peneira (Tyler) }\end{array}$ & $\begin{array}{c}\text { Menor abertura } \\
(\boldsymbol{\mu m})\end{array}$ & $\begin{array}{c}\text { Massa retida } \\
(\%)\end{array}$ \\
\hline 1 & 48 & 295 & 0,3 \\
\hline 2 & 17 & 208 & 5,3 \\
\hline 3 & 35 & 147 & 9,0 \\
\hline 4 & 50 & 104 & 12,6 \\
\hline 5 & 120 & 53 & 21,3 \\
\hline 6 & 130 & 38 & 6,0 \\
\hline 7 & -400 & & 45,4 \\
\hline
\end{tabular}

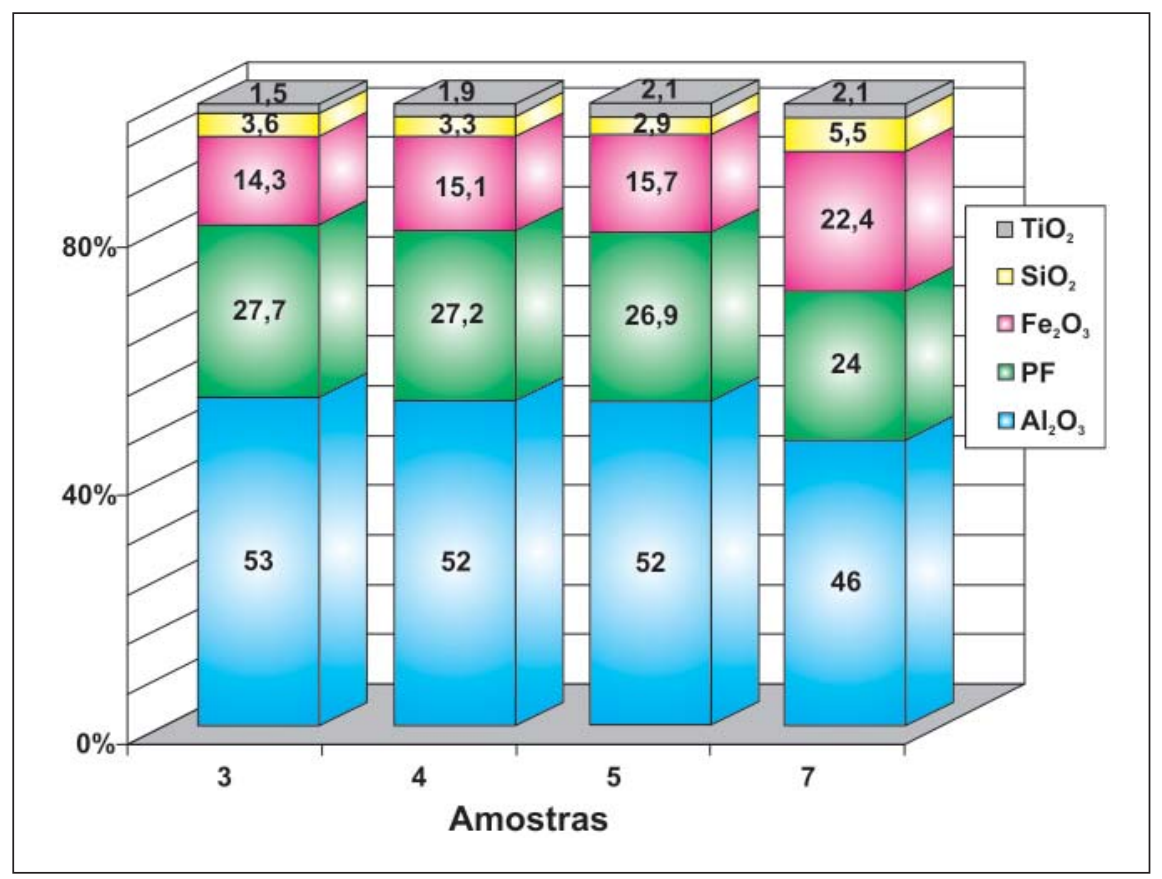

Figura 1 - Resultados da análise semiquantitativa de fluorescência de raios $X$ de algumas amostras separadas na análise granulométrica da bauxita (Tabela 1). Os percentuais de $\mathrm{ZrO}_{2}$, $\mathrm{MnO}$ e $\mathrm{P}_{2} \mathrm{O}_{5}$ estavam abaixo de $0,4 \%$ e foram omitidos do gráfico. 
de gibbsita e caulinita presentes possa ser feita, é necessária a utilização de outras metodologias de análise, como a especiação química, ou a aplicação do método de Rietveld, para que as fases minerais possam ser quantificadas a partir dos dados de DRX.

Na Figura 2, observa-se uma seqüência de fotomicrografias da amostra 7 (fração mais fina), em que são constatadas a heterogeneidade morfológica da amostra e a presença de agregados recobertos por partículas de menor tamanho e de formato característico da caulinita. Mediante uma análise pontual de um desses agregados (Figura $2 \mathrm{C}$ ) com detector EDS, verificou-se a presença de alumínio e silício numa partícula menor mais externa (Figura 2 C, 2) e também, foi verificada a presença de apenas alumínio na estrutura maior (Figura 2 C, 1), reforçando a hipótese de que as partículas de caulinita recobrem as partículas de gibbsita. É esperado que a caulinita e a gibbsita formem agregados quando estiverem em suspensão, considerando que, no $\mathrm{pH}$ da polpa $(6,8)$, esses minerais devam ter carga superficial oposta (Hou et al., 2007).

O efeito do período de assentamento, na formação e consolidação do sedimento, a partir da polpa de bauxita, foi observado através das curvas de tensão versus tempo de análise (Figura 3). Como o tempo de análise é diretamente proporcional à deformação sofrida pelo sedimento, as curvas possuem o mesmo perfil característico das curvas de tensão versus deformação, obtidas para pós (Orband \& Geldart, 1997). Em ambos os casos, a interpretação do comportamento é a mesma - inicialmente, em níveis muito baixos de deformação, a resistência do material aumenta até um ponto de máximo (yield point), em que ocorre a ruptura da estrutura, ou seja, as forças coesivas são superadas. Em seguida, ocorre o alívio da tensão e sua manutenção num patamar que está relacionado com a resistência friccional do deslocamento das partículas umas sobre as outras.

Como a quantidade de partículas sedimentadas aumenta com o período
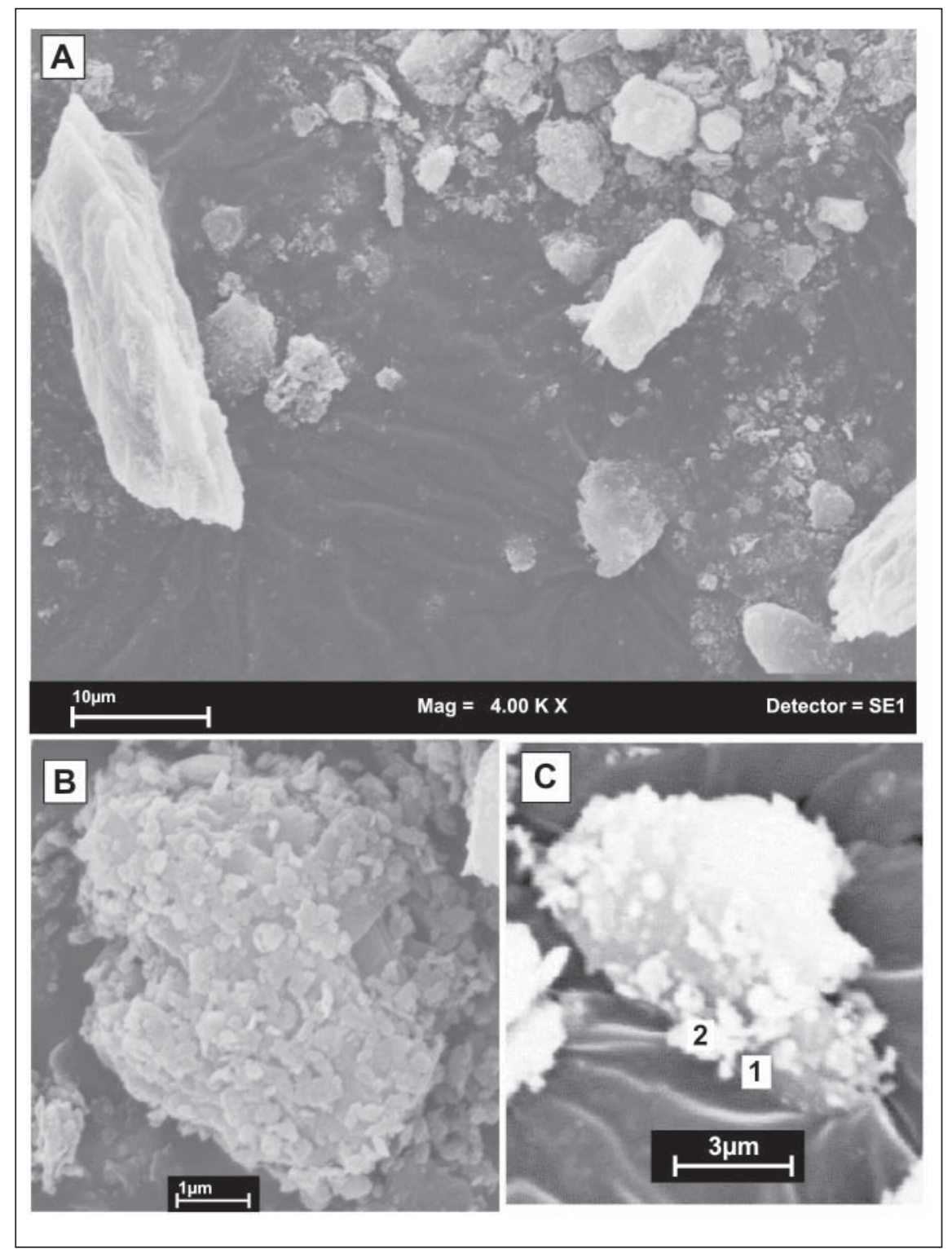

Figura 2 - Fotomicrografias da fração fina (amostra 7) da bauxita.

de assentamento, observa-se um contínuo aumento nos níveis das tensões até o término do fluxo de massa para o sedimento. As curvas obtidas, para as amostras sedimentadas por 4 e 24 horas, ocorreram no mesmo patamar de tensões (Figura 3), indicando que o final da sedimentação ocorre entre 2 e 4 horas. Esses resultados, contudo, não podem ser relacionados com a turbidez residual, pois a massa das partículas que porventura possam ainda estar em suspensão é muito pequena. Um ligeiro acréscimo na tensão de ruptura, que ocorre no período de 4 a 24 horas de assentamento, pode estar associado a um processo de organização interna dessas partículas, que tendem a assumir uma configuração mais estável.

A carga superficial de óxidos e silicatos pode ser modificada pela variação da concentração das espécies $\mathrm{H}^{+}$e $\mathrm{OH}^{-}$ (Cunha et al., 2007), ocasionando a mudança das interações entre as partículas, o que pode, indiretamente, influenciar na velocidade de sedimentação (pela modificação do tamanho dos agregados) e na coesão do sedimento formado. Contudo, a elevação do $\mathrm{pH}$ de 6,8 para 9,5 , pela adição de $\mathrm{NaOH}$, não alterou, de forma 
significativa, os resultados obtidos para o período de assentamento de duas horas, indicando que as variações da carga superficial das partículas ocorridas nessa faixa de $\mathrm{pH}$ não interferem no processo.

\section{Conclusões}

O método reológico foi satisfatório para o acompanhamento do processo de sedimentação/consolidação da polpa de bauxita.

O minério de bauxita era composto, predominantemente, por gibbsita, hematita e caulinita e continha cerca de $45 \%$ das partículas tem tamanho inferior a $38 \mu \mathrm{m}$. Foi demonstrado, pelas curvas de tensão versus tempo, que, antes de 4 horas, praticamente, todo material já havia sedimentado. Após 24 horas de assentamento, ocorreu um ligeiro acréscimo da tensão na ruptura do sedimento.

\section{Agradecimentos}

A autora agradece ao CETEM e ao $\mathrm{CNPq}$ por todo apoio dado a esse trabalho.

\section{Referências bibliográficas}

ARAÚJO, D. G., NASCIMENTO, C. R. Efeito da aditivação nas propriedades reológicas e nas características de sedimentação da polpa de bauxita - I Ensaios Preliminares. In: JORNADADE INICIAÇÃO CIENTÍFICADO CETEM/ MCT, 16. Anais... 2008. p. 22-28.

BHATTACHARYA, I.N., PANDA, D., BANDOPADHYAY, P. Rheological behaviour of nickel laterite suspensions, Int. J. Miner. Process, v.53, p. 251-263, 1998.

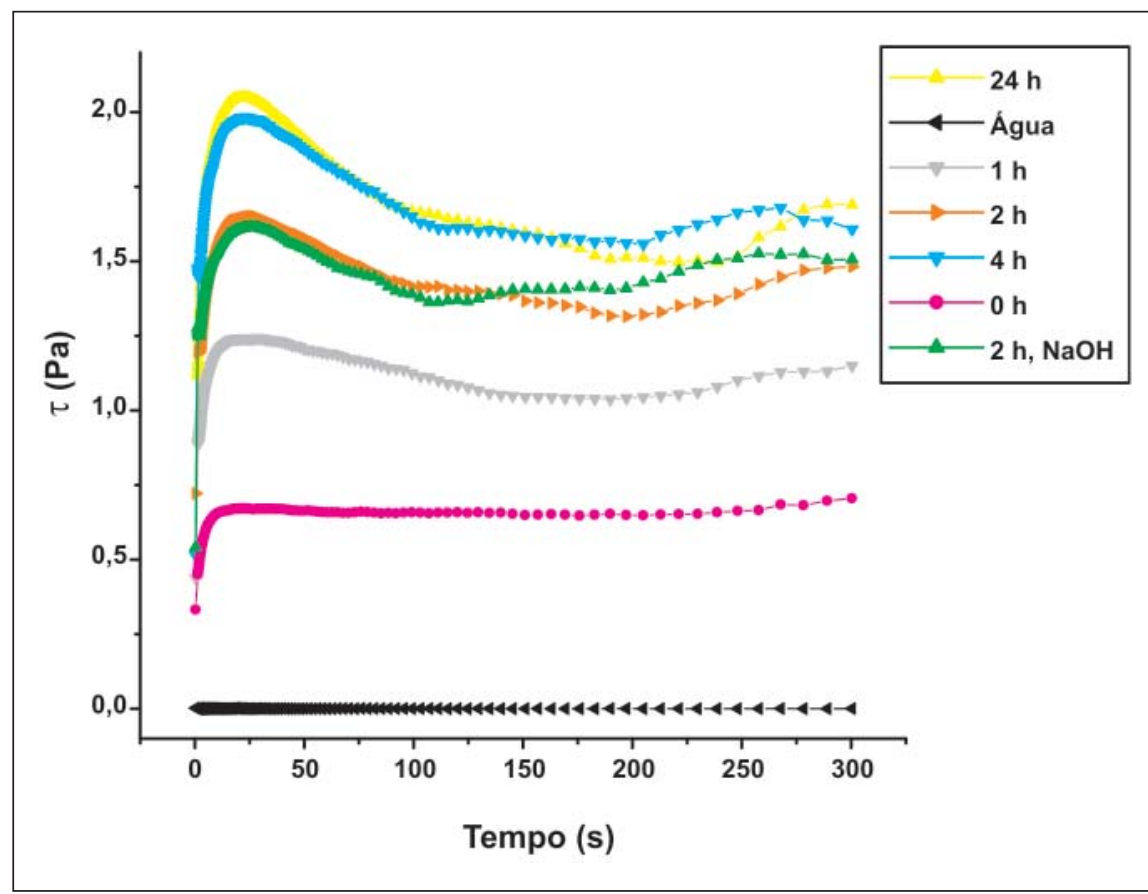

Figura 3 - Curvas de tensão $(\tau)$ versus tempo de análise para a água e amostras de polpa de bauxita após diferentes períodos de assentamento.

BOUDREAU, B. P., BENNETT, R. H. New Rheological and Porosity Equations for SteadyState Compaction, American Journal of Science, v. 299, p. 517-528, 1999.

BRAGANÇA, A.C., SILVA, T.A. Alternative to Lime as a Rheology Modifier in the Transport of Iron Ore Slurry by the Samarco Pipeline, Hydrotransport 17. In: INTERNATIONAL CONFERENCE ON THE HYDRAULIC TRANSPORT OF SOLIDS, 17. 2007, p. $29-38$.

CUNHA, F. O., TOREM, M. L., D’ABREU, J. C. A Influência do pH na reologia de polpas de caulim. Rem - Revista Escola de Minas, v.60, n.3, p. 505-511, 2007.

DANKERS, P.J.T., WINTERWERP, J.C. Hindered settling of mud flocs: theory and validation. Continental Shelf Research, v. 27, p. 1893-1907, 2007.

DZUY, N.Q., BOGER, D. V. Direct yield stress measurement with the Vane Method. Journal of Rheology, v.29, p. 335-347, 1985.

HOU, T., XU, R., ZHAO, A. Interaction between electric double layers of kaolinite and $\mathrm{Fe} /$ Al oxides in suspensions. Colloids and Surfaces A: Physicochem. Eng. Aspects, v.297, p. 91-94, 2007.

MATOUSEK, V. Research developments in pipeline transport of settling slurries. Powder Technology, v. 156, p. 43-51, 2005.

ORBAND, J.L.R., GELDART, D. Direct measurement of powder cohesion using a torsional device. Powder Technology, v. 92, p. 25-33, 1997.

TORFS, H., MITCHENER, H., HUYSENTRUYT, H., TOORMAN, E. Settling and consolidation of mud/sand mixtures. Coastal Engineering, v. 29, p. 27-45, 1996.

Artigo recebido em 08/08/2008 e aprovado em 04/11/2009.

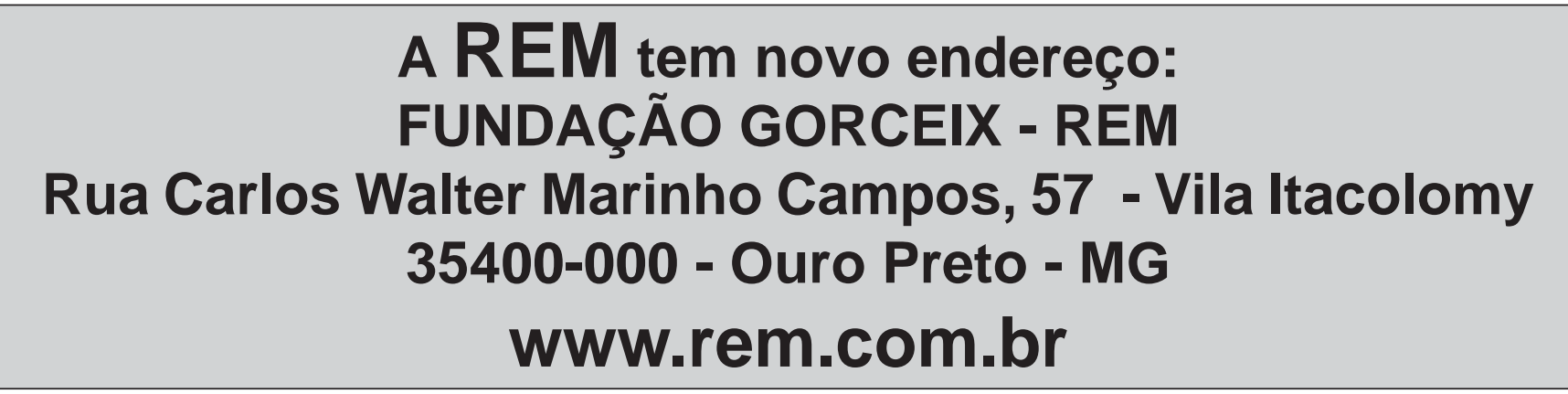

